\title{
The effect of microstructural heterogeneities on the High Cycle Fatigue scatter of cast aluminium alloys: from an elementary volume to the structure
}

\author{
Driss EL KHOUKHI ${ }^{1,2,3,{ }^{*}, \text { Franck MOREL }}{ }^{1}$, Nicolas SAINTIER $^{2}$, Daniel BELLETT ${ }^{1}$ and Pierre OSMOND ${ }^{3}$ \\ ${ }^{1}$ LAMPA, Arts et métiers Paris Tech, 49100 Angers, Cedex, France \\ ${ }^{2}$ I2M, Arts et métiers Paris Tech, 33170 Bordeaux, Cedex, France \\ ${ }^{3}$ PSA Groupe, 92250 La Garenne-Colombes, Cedex, France
}

\begin{abstract}
Cast Al-Si alloys have been widely used in automobile applications thanks to their low density and excellent thermal conductivity. A lot of components made of these alloys are subjected to cyclic loads which can lead to fatigue failure. Furthermore, the well know size effect in fatigue, whereby the fatigue strength is reduced in proportion to an increase in size, can be important. This is caused by a higher probability of initiating a crack in larger specimens (i.e. statistical size effect). This paper analyses the role of casting defects on the statistical size effect. For that, a uniaxial fatigue testing campaign $(\mathrm{R}=0.1)$ has been conducted using two cast aluminium alloys, fabricated by different casting processes (gravity die casting and lost foam casting), associated with the $\mathrm{T} 7$ heat treatment, and with different degrees of porosity. Different specimens (smooth and notched) with different stressed volumes have been investigated. The first part of this article is dedicated to the experimental characterization of the statistical size effect in both alloys via the concept of the Highly Stressed Volume. The second part investigates the effect of the Highly Stressed Volume on the critical defect size via diagram of Kitagawa-Takahashi. The results show that the presence of statistical size effect is strongly linked to the characteristics of the pore population present in the alloy. A numerical approach, linking the observed pore distribution to the volume of loaded material, is proposed and discussed.
\end{abstract}

\section{Introduction}

\subsection{Context and objectives}

This work focuses on cast Al-Si alloys, widely used in the automotive industry. In order to manufacture engine components, the PSA Groupe uses two foundry processes that result in components containing Microstructural Heterogeneities (MH) with different characteristics. These Microstructural Heterogeneities control the fatigue behaviour of these Al-Si alloys. These components are subjected to cyclic mechanical loads (in High Cycle Fatigue) that can result in the appearance of cracks and thus lead to the failure of the structure. The effect of the $\mathrm{MH}$ on the fatigue behaviour has been well documented in references [1-3].

A typical engineering design practice [4] involves the identification of the fatigue criteria, used to size and validate real components, based on tests carried out on laboratory specimens, which have a specific volume, under simple loading modes (tension, bending, and torsion). However, real component loading conditions often prove to be different from those applied to laboratory test specimens, particularly in terms of the size of the critical zone (size effect) and the homogeneity of the stress state in this zone (stress gradient effect). Hence, the industrial objective of this work is to develop predictive tools to ensure the passage from an elementary volume to the structure taking in account the size and stress gradient effects. In particular, the effect of microstructural heterogeneities, principally shrinkage porosity, on the statistical size effect in cast Al-Si alloys is investigated.

\subsection{State of the art}

It is well known that the fatigue strength of certain materials decreases with an increase in the volume [6-7]. This is referred to as either the "volume effect", the "size effect" or the "scale effect" and is often simply explained by an increase in the probability of encountering a large material defect. The effect is influenced by factors related to the random distribution of defects in the material and the impact of the manufacturing process on the homogeneity of the material.

Kloos et al. [8] has classified the size effect phenomenon into the following categories: (i) statistical size effect induced by the high probability of defects in larger specimens, (ii) geometrical size effect attributed to stress inhomogeneity from different notch types, (iii) production size effect generated by production technology and (iv) surface size effect caused by the surface characteristics such as roughness. 
For Makkonen [9] the size effect can be explained by the statistical size effect using the Weibull [10] approach and the weakest link theory. Makkonen [9] experimentally showed the influence of the statistical size effect on the high cycle fatigue behaviour of both smooth and notched cylindrical specimens.

The Highly Stressed Volume (HSV) approach was first introduced by Kuguel [11] in 1961, and then employed by Sonsino and Fischer [12], and others [13]. The terminology $\mathrm{Vn} \%$ is used to define the volume of material that is subjected to at least $\mathrm{n} \%$ of maximum stress $(\sigma \mathrm{n} \%=\mathrm{n} \% \times \sigma \max )$. This volume of material is assumed to have an increased probability of fatigue crack initiation. The percent is assumed to be $95 \%$ by Kuguel [11] and $90 \%$ by Sonsino and Fisher [12]. The concept has been verified for metallic components with good success using the V90\% volume. For short-fiber reinforced specimens and components, a value of $\mathrm{V} 80 \%$ proved to be more appropriate than $\mathrm{V} 90 \%$.

In the present work the influence of the statistical size effect on the fatigue strength of cast aluminium alloys is investigated using the HSV concept. A value of V80\% is used for the reason explained in section 2.4.

Due to its significance in structural reliability, certain design standards require that the statistical size effect be taken into consideration [14-15]. Even so, at the present time, it remains an open topic of discussion in the scientific literature, in particular with respect to the HCF strength cast Al-Si alloys. Therefore, in this work an indepth assessment of the statistical size effect on the HCF strength of two cast Al-Si alloys, is underway with the aim of developing a predictive model, based on the theory of Monte-Carlo, to evaluate the size effect using knowledge of the defect population.

Two Al-Si alloys with different porosity distributions were chosen in order to understand how the characteristics of the defect populations affect the statistical size effect. Different specimen shapes, including both smooth and notched specimens have been machined from these alloys, in order to obtain geometries with different Highly Stressed Volumes. High cycle fatigue tests were conducted to investigate the size effect on the fatigue strength using the HSV concept. Fractography analyses were conducted to investigate the relationship between the critical defects and the fatigue strength via the Katagawa-Takahashi diagram.

\section{Experimental investigation}

\subsection{Materials}

To study the effect of casting defects on the statistical size effect, two cast aluminium alloys, referred to as alloys $\mathrm{A}$ and $\mathrm{B}$, were used [Fig. 1]. These alloys were fabricated by different casting processes (gravity die casting and lost foam casting), associated with the T7 heat treatment [Table1]. Each process results in different porosity populations (i.e. volume fraction, defect size...) and different mechanical properties [Table2].
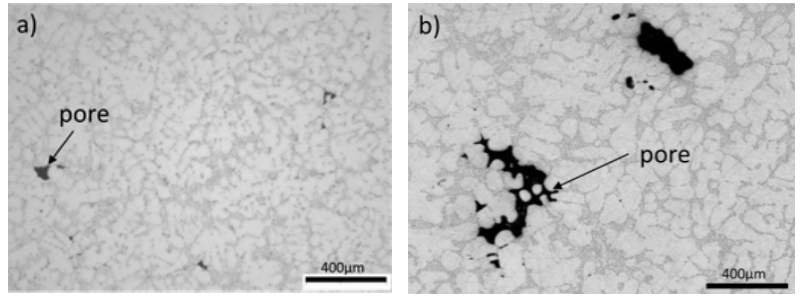

Fig. 1. Microstructure of the alloys (a) A alloy and (b) B alloy

Table 1. Chemical composition, casting process and heat treatment of the two alloys

\begin{tabular}{|c|c|c|c|}
\hline Alloy & $\begin{array}{c}\text { Chemical composition } \\
(\mathrm{wt})\end{array}$ & Process & $\begin{array}{c}\text { Heat } \\
\text { treatment }\end{array}$ \\
\hline $\mathrm{A}$ & $\begin{array}{c}7 \% \mathrm{Si}, 0.3 \% \mathrm{Mg}, \\
0.5 \% \mathrm{Cu}, \mathrm{Al} \mathrm{Rem} .\end{array}$ & $\begin{array}{c}\text { Gravity Die } \\
\text { Cast }\end{array}$ & $\mathrm{T} 7$ \\
\hline $\mathrm{B}$ & $\begin{array}{c}7 \% \mathrm{Si}, 0.3 \% \mathrm{Mg}, \mathrm{Al} \\
\text { Rem. }\end{array}$ & $\begin{array}{c}\text { Lost Foam } \\
\text { Cast }\end{array}$ & $\mathrm{T} 7$ \\
\hline
\end{tabular}

Table 2. Mechanical properties of the two alloys

\begin{tabular}{|c|c|c|c|}
\hline Alloy & SDAS $(\mu \mathrm{m})$ & $\begin{array}{c}\text { Micro-hardness } \\
(\mathrm{Hv} 0.025)\end{array}$ & $\sigma_{Y 0.2 \%}(\mathrm{MPa})$ \\
\hline A & $42.3 \pm 9.7$ & $113.8 \pm 2.8$ & $260.4 \pm 1.6$ \\
\hline B & $77.3 \pm 18.9$ & $99.0 \pm 9.0$ & $240.1 \pm 4.5$ \\
\hline
\end{tabular}

In the work of LE [1] these alloys were characterised in terms of their casting defect size distributions using the Murakami method with a standard inspection area of $\mathrm{S}_{0}=2.55 \mathrm{~mm}^{2}$.

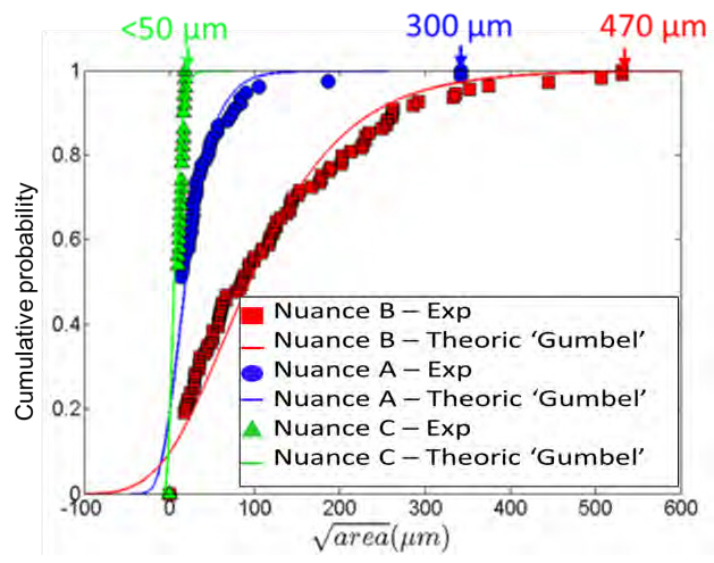

Fig. 2. Defect size distributions of the three alloys using the Murakami Method

Fig 2 shows the defect size distributions for three alloys, $\mathrm{A}, \mathrm{B}$ and $\mathrm{C}$. Note that alloy $\mathrm{C}$ used by LE corresponds to alloy B subjected to High Isostatic Pressing (HIP). The maximum defect sizes observed on the polished surfaces of alloys A and B are $300 \mu \mathrm{m}$ and $470 \mu \mathrm{m} .80 \%$ of the defects in alloy A have an $\sqrt{ }$ Area lower than $50 \mu \mathrm{m}$ and $20 \%$ of the defects in alloy B have a $\sqrt{ }$ Area greater than $200 \mu \mathrm{m}$. 


\subsection{Experimental conditions}

All fatigue tests were performed in uniaxial tension with stress ratio $\mathrm{R}=0.1$ using a Rumul Testronic resonant testing machine at approximately $100 \mathrm{~Hz}$. The stopping criterion used is a drop in the resonance frequency of 1 $\mathrm{Hz}$, corresponding to the presence of a fatigue crack of approximately $2 \mathrm{~mm}$. All tests were performed at room temperature in a laboratory air environment. The tests were conducted following the staircase technique with a maximum life of $2 \times 10^{6}$ cycles. The not-failed samples were retested until failure in order to identify the critical defect that initiates a crack. A step of $5 \mathrm{MPa}$ stress amplitude is used in the staircase procedure.

\subsection{Specimens geometry}

To study the effect of volume on the fatigue strength of alloys A and B, different fatigue specimen geometries were defined, corresponding to different loaded volumes. They are referred as: "V1-Small Volume", "V2Reference Volume", "V3-Large Volume" and "VEENotch specimen" (Fig. 3).

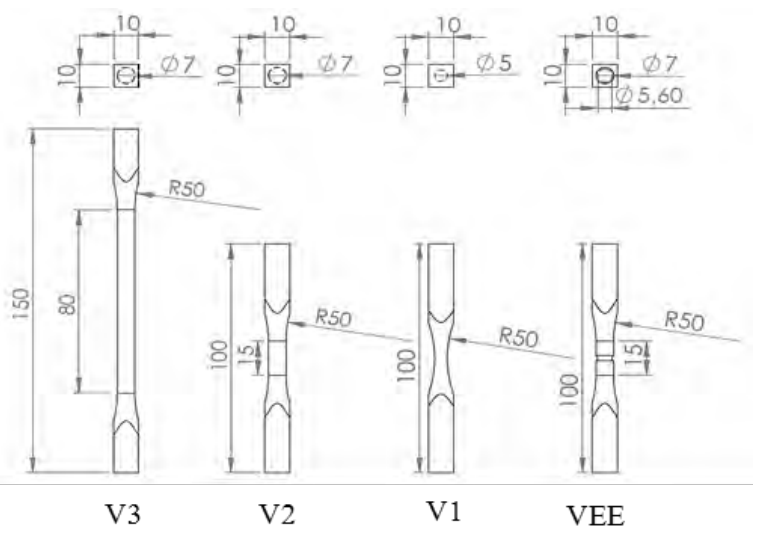

Fig. 3. Specimens for tensile fatigue tests

\subsection{Estimation of the Critical Volume}

In the following the estimated critical volume is chosen taking into account the combination of two criteria:

- The damage mechanism: observations of the fatigue failure surfaces of the specimens show that $90 \%$ of the critical defects are located in a sub-surface layer with a thickness of about 500 micrometers.

- Stress heterogeneity: A Highly Stress Volume of V80\% is chosen. The justification for choosing this value is that some of the V1 specimen which has an hourglass shape broke in zones where the stress level is approximately $80 \%$ less than the maximum principal stress $\sigma_{\text {Imax }}$ at the centre of the specimen. Figure 4 shows the case of a specimen in which the fatigue crack is located approximately $5.2 \mathrm{~mm}$ from the middle of the specimen.

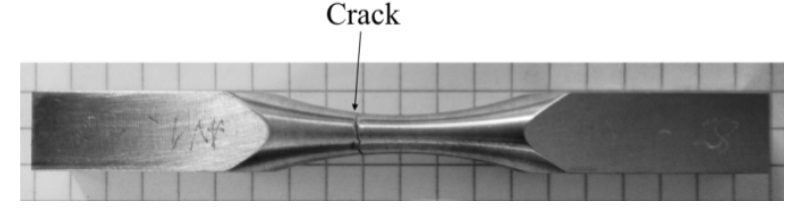

Fig. 4. V1 sample showing a crack after failure

The combination of the two criteria above gives a highly stressed volume of $0.8 \times \sigma_{\text {Imax }}$ located in a subsurface layer of thickness $500 \mu \mathrm{m}$. In the following section, this definition is referred to as the Critical Volume $(\mathrm{Vc})$. For each specimen geometry, the estimation of the Highly Stressed Volume was performed using a general purpose finite element code. For a static load, the highly stressed zones in each specimen are identified by linear elastic finite element analysis. Finite element models of the specimens are shown in Fig. 5.

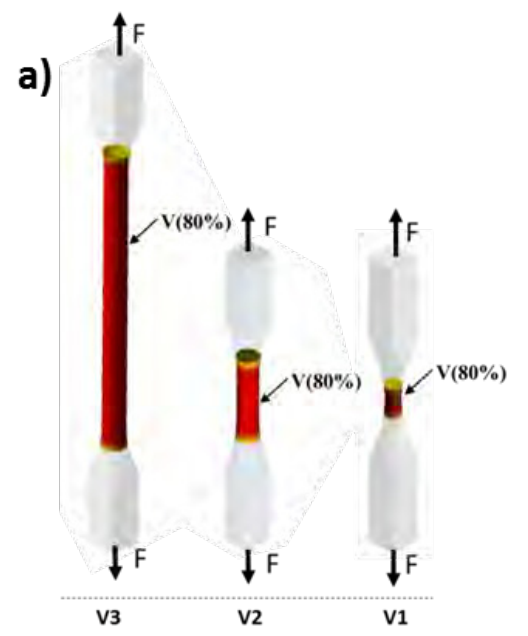

b)

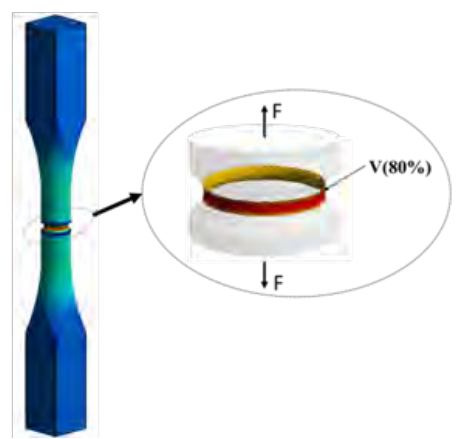

Fig. 5. Highly stressed volume for (a) smooth specimens V1, $\mathrm{V} 2$ and V3 and (b) notched specimens

After determination of the highly stressed volume, and in order to take in account the damage mechanism, an analytical calculation was conducted to estimate the critical volume $(\mathrm{Vc})$ under a layer of $500 \mu \mathrm{m}$. The critical volume corresponding to each sample and other characteristics are shown in Table 3. 
Table 3. Characteristics of the samples

\begin{tabular}{|c|c|c|c|c|}
\hline \multirow{2}{*}{ Sample } & \multicolumn{2}{|c|}{ Number of specimens } & \multirow{2}{*}{ Kt } & $\begin{array}{c}\text { Vc } \\
{\left[\mathrm{mm}^{3}\right]}\end{array}$ \\
\cline { 2 - 3 } & Alloy A & Alloy B & & 4.80 \\
\hline VEE & 5 & 5 & 1.78 & 90 \\
\hline V1 & 13 & 3 & 1 & 920 \\
\hline V2 & 13 & 4 & 1 & 320 \\
\hline V3 & 12 & 0 & 1 & 912 \\
\hline
\end{tabular}

\section{Results}

\subsection{Mechanical results}

The fatigue strength of specimens V1, V2 and V3 of alloy A were estimated using the Dixon-Mood [16] method. For the notched specimens (VEE) of alloy A and all of specimens of alloy B the fatigue strengths were estimated using the method proposed by Houria et al. [17] because of the small number of tests.

The product of the nominal stress amplitude $\sigma_{\mathrm{a}}$ and stress concentration factor $\mathrm{K}_{\mathrm{t}}$ gives the local stress amplitude at the notch-tip. In [18-20] it was shown, that there is a continuous relationship between the fatigue strength expressed as $\mathrm{K}_{\mathrm{t}} \sigma_{\mathrm{a}}$ and the highly stressed volume. In this work, it will be correlated to the critical volume Vc.

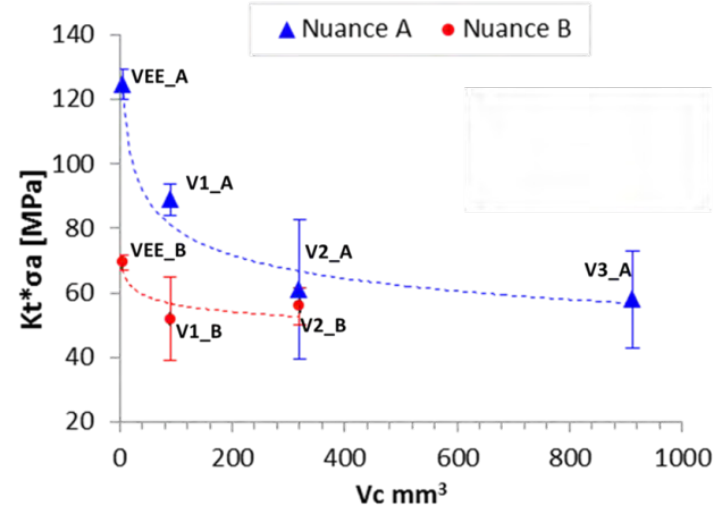

Fig. 6. Relationship between highly stressed volume and local stress amplitude for A and B alloys

Fig. 6 shows the effect of highly loaded volume $(\mathrm{Vc})$ on the local fatigue strength amplitude $\mathrm{Kt}^{*} \sigma a$ for a stress ratio of $\mathrm{R}=0.1$ at $2 \times 10^{6}$ cycles for $50 \%$ probability of failure. For both alloys, the local fatigue strength amplitude decreases with increasing critical volume Vc. The notched specimens have the highest strength in terms of the local stress amplitude. This can be explained by the fact that the probability of failure decreases with a smaller material volume, the local stress amplitude is higher than for bigger material volumes such as the axially loaded smooth specimens with homogeneous stress distributions (V1, V2 and V3).

It is also noted, that for alloy A, the dependence on the critical volume is more pronounced compared to alloy B. For alloy A, saturation of the volume effect occurs at a specific volume of $320 \mathrm{~mm}^{3}$. Following these observations, it can be concluded that:

- the alloy A has a more pronounced volume effect than alloy B. This is probably due to the characteristics of the defect population (i.e. pore size, distance between large pores, etc....).

- for alloy A, the fatigue strength becomes stabilized from a specific volume of $320 \mathrm{~mm}^{3}$. This could be considered as the Fatigue Representative Elementary Volume of the alloy A.

- for alloy $\mathrm{B}$, the fatigue strength stabilizes rapidly at a specific volume of $90 \mathrm{~mm}^{3}$, which can be considered as the REV of the B alloy.

An analysis of the critical defects on the fatigue failure surfaces can confirm this tendency.

\subsection{Kitagawa-Takahashi diagram}

SEM microscopy was used to measure the $\sqrt{\text { Area }}$ parameter of the critical defects on the fatigue failure surfaces of tested specimens. It was observed that for the four notched specimens of the B alloy, the fracture surfaces show two initiation sites (Site 1 and Site 2). This result reflects the higher density of large pores in alloy B even in a small critical volume (Fig. 7).

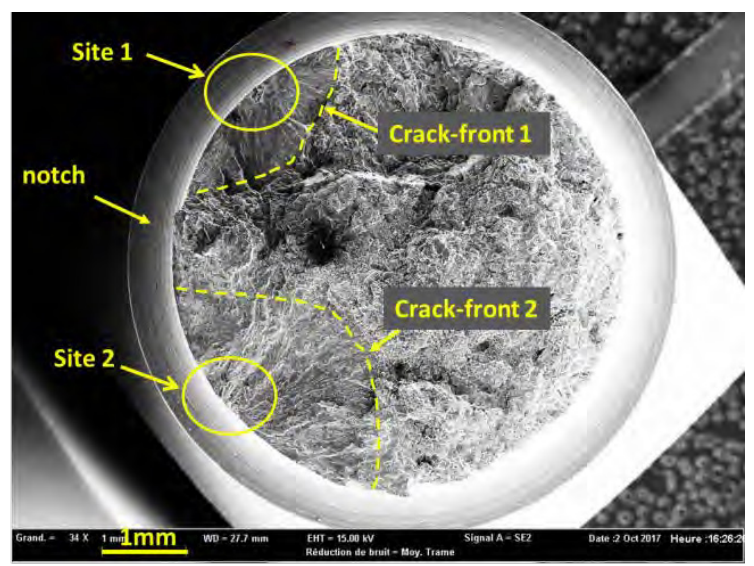

Fig. 7. Fatigue fracture surface of a notched specimen from the B alloy

The summary of the size of critical defects present on the fatigue fracture surface of notched samples from the B alloy are shown in the Table 4.

Table 4. Critical defects for notched specimens of the B alloy

\begin{tabular}{|c|c|c|}
\hline Specimen & $\begin{array}{c}\text { Aarea : Site 1 } \\
{[\boldsymbol{\mu m}]}\end{array}$ & $\begin{array}{c}\text { VArea : Site 2 } \\
{[\boldsymbol{\mu m}]}\end{array}$ \\
\hline VEE_B_01 & 176 & 248 \\
\hline VEE_B_02 & 243 & 333 \\
\hline VEE_B_03 & 204 & 320 \\
\hline VEE_B_04 & 176 & 330 \\
\hline
\end{tabular}

To link the fatigue strength of the samples to the critical defects size, Kitagawa-Takahashi diagrams were established. The estimation of fatigue strength of each specimen was carried out using the Houria et al. Method. The results are represented on Fig.8. 


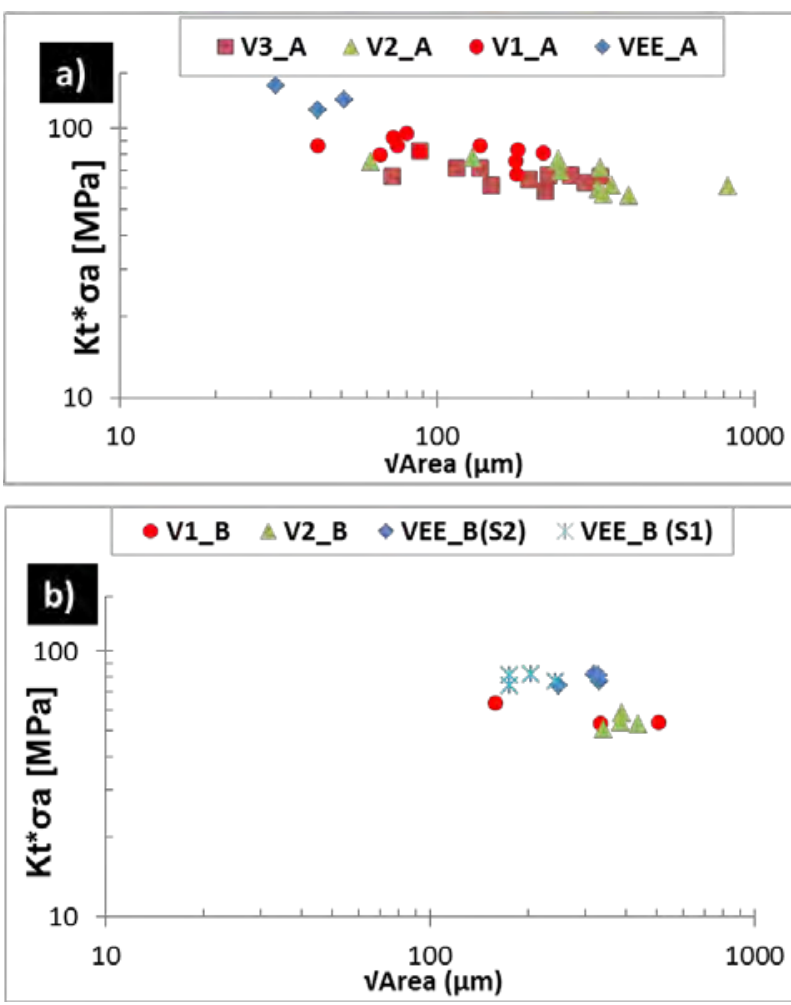

Fig. 7. Kitagawa-Takahashi diagram with $R=0.1$ (a) for the A alloy (b) for the B alloy.

From Fig. 7, the following conclusions can be made: i) The fatigue strength of alloy A [Fig.7, a] has a tendency to decrease when the size of the critical defects increases. Note also that the size of the critical defects increases when the critical volume increases. Indeed, the notched specimens (VEE) with the lowest critical volume $\left(4.80 \mathrm{~mm}^{3}\right)$ have the smallest defect sizes. By changing to a critical volume of $90 \mathrm{~mm}^{3}$ for the V1 specimens then to $320 \mathrm{~mm}^{3}$ for the V2 specimens, the size of the critical defects has a tendency to increase and the fatigue strength drops.

ii) Between specimens of size V2 and V3, there is almost no difference in the average value of the fatigue strength. It can be concluded that the fatigue strength is stabilised, most probably due to the saturation in the maximum size of the critical defects [Fig.7, a].

iii) The size of the critical defects in alloy $\mathrm{B}$ is relatively large for all types of tested specimens. Their $\sqrt{ }$ Area are greater than $160 \mu \mathrm{m}$. For this range of defect size, the fatigue strength of the specimens does not change significantly compared to the variation in alloy A [Fig.7, b].

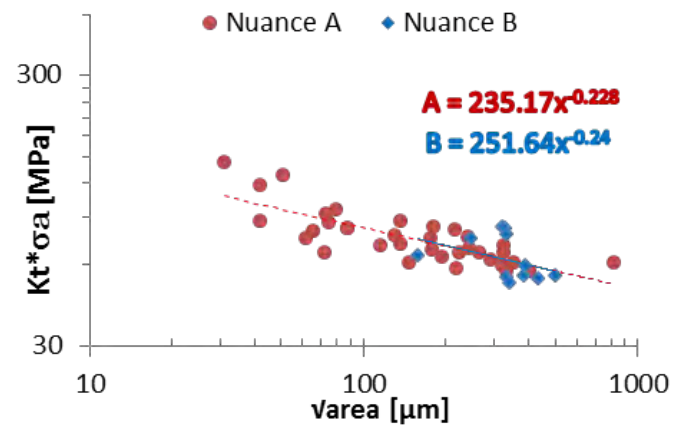

Fig. 8. Kitagawa-Takahashi diagram $(\mathrm{R}=0.1)$
Fig. 8 shows the Kitagawa-Takahashi diagram in terms

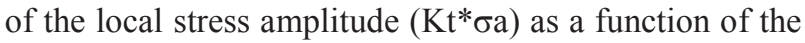
square root of the critical defect size. The points on the graph are the critical defects observed on the fatigue failure surfaces of the tested specimens of the two alloys. Note that, for the notched specimens of alloy B (with multi-site initiation), only the largest defect is shown in Fig 8.

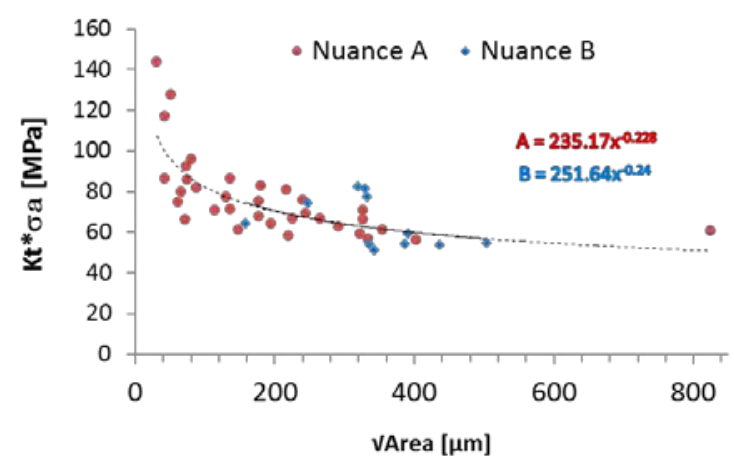

Fig. 9. Kitagawa-Takahashi diagram $(\mathrm{R}=0.1)$

From the Kitagawa-Takahashi diagram represented in linear axes on (Fig. 9), a better understanding of the weak presence of the size effect in alloy B can be seen. The critical defects are generally at the level where the fatigue strength begins to stabilize. Therefore, and since the size of the critical defects remain relatively large ( $\sqrt{\text { Area greater than }} 160 \mu \mathrm{m})$, the difference in the fatigue strength remains low. Indeed, when the size goes from $160 \mu \mathrm{m}$ to $825 \mu \mathrm{m}$ the local stress amplitude goes from approximately $67 \mathrm{MPa}$ to $60 \mathrm{MPa}$ (Fig. 8). So, even for the different specimen sizes, the strength does not significantly change, hence the weak size effect. Also from Fig. 8 two parallel trend lines are obtained for the two materials. The parallelism indicates that the failure in both alloys is controlled by the same mechanisms.

Normally, the fatigue strength of the B alloy is lower than that for the A alloy, due to the traces of Copper present in the A alloy [Table 1]. But in the Fig. 8 and Fig. 9 the curves are almost superimposed. This is can be explained by the lower number of specimens tested in the B alloy.

\section{Modelling approach}

A modelling approach, linking the observed pore distribution to the volume of loaded material is in the process of development. The basic methodology is to use the Monte-Carlo theory to understand the relationship between the size effect and the parent defect distribution (size and spatial distribution) for a cast material. It is hoped that this approach will also yield insight in the experimentally observed scatter in the fatigue data. The principal steps in the modelling approach are:

- Identification of the parent defect population based on experimental observations (tomography or optical microscopy). 
- Generation of synthetic material with the parent defect distribution.

- Sampling of different sized volumes from the synthetic material.

- Statistical extreme value analyses to determine the extreme value distribution of the critical defects for different volumes.

- Use of an appropriate fatigue criterion to define the relationship between the defect size and the fatigue strength for different volumes.

The parent distributions for both alloys are derived from micro-tomography analysis. Synthetic materials, of

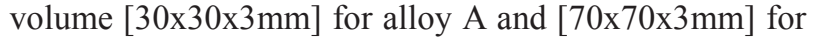
alloy $\mathrm{B}$, were formed with these parent distributions. These volumes are equivalent to the volumes scanned via micro-tomography [Fig. 10]. The pore positions are generated randomly within the synthetic material. Sampling volumes (SVi) are then taken randomly from the parent synthetic material [Fig. 11]. Then, extreme values analyses were conducted on these volumes. Note that, for the volumes SV1 to SV5, only a sub-surface volume is considered in the analysis (i.e. a hollow cylindrical volume including the exterior surface and a thickness of $0.5 \mathrm{~mm}$ ). The volumes SV6 to SV8 are used to determine the stabilized extreme value distribution of each material. The dimensions of these volumes are summarized in [Table 5]. This process is repeated 10000 times according to the Monte Carlo principle. The distributions of the extreme values corresponding to the critical defect size are shown in Fig. 12.

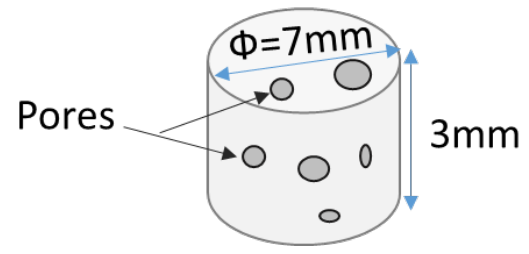

Fig. 10: Schematic representation of Micro-tomographic scanned volumes

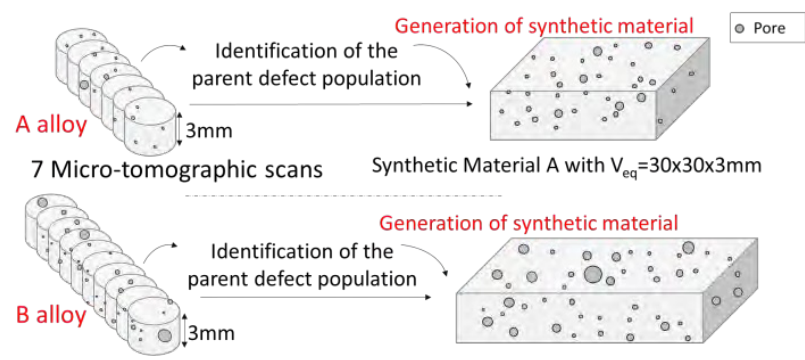

10 Micro-tomographic scans Synthetic Material B with Veq $=70 \times 70 \times 3 \mathrm{~mm}$

Fig. 11: Principle of identification of parent defect population and generation of synthetic materials for both alloys A and B.

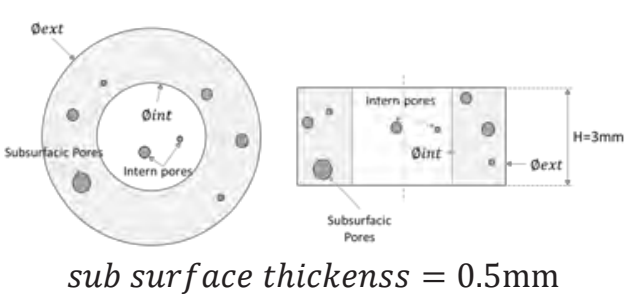

Fig. 12: Definition of the sampling volume

Table 5: Sampling volumes

\begin{tabular}{|c|c|c|c|}
\hline $\begin{array}{c}\text { Sampling } \\
\text { Volume }\end{array}$ & Rint [mm] & Rext [mm] & Volume [mm3] \\
\hline SV1 & 2 & 2.5 & 21 \\
\hline SV2 & 3 & 3.5 & 31 \\
\hline SV3 & 3.5 & 4 & 92 \\
\hline SV4 & 9.5 & 10 & 139 \\
\hline SV5 & 14.5 & 15 & 2121 \\
\hline SV6 & 0 & 15 & 4882 \\
\hline SV7 & 0 & 70 & 46181 \\
\hline SV8 & 0 & 80 & 60319 \\
\hline
\end{tabular}

\subsection{Numerical results}

In the following, the preliminary results of this approach are presented. Specifically, the results of the extreme value analyses of the critical defect size as a function of the sampling volume are discussed in order to explain the observed experimental tendencies.

Fig. 13 presents the results of the extremes value analysis of the distribution of the critical defects for different sampled volumes (SVi) in alloys A and B. It can be seen that the extreme value distributions are associated with the larger defects in the tail of the parent distributions. For alloy B, the extreme value distribution is flatten out when the sample volume is increased and tends towards a stabilized distribution (Fig. 13b). For alloy A, the opposite trend is observed. That is, the distribution becomes narrower when increasing the sample volume from SV1 to SV8 and it also tends towards a stabilized distribution (Fig. 13a). It can be seen that the mean critical defect size, as a function of volume, for alloy A remains less than $100 \mu \mathrm{m}$. But for alloy B, it goes from $167 \mu \mathrm{m}$ to $712 \mu \mathrm{m}$.

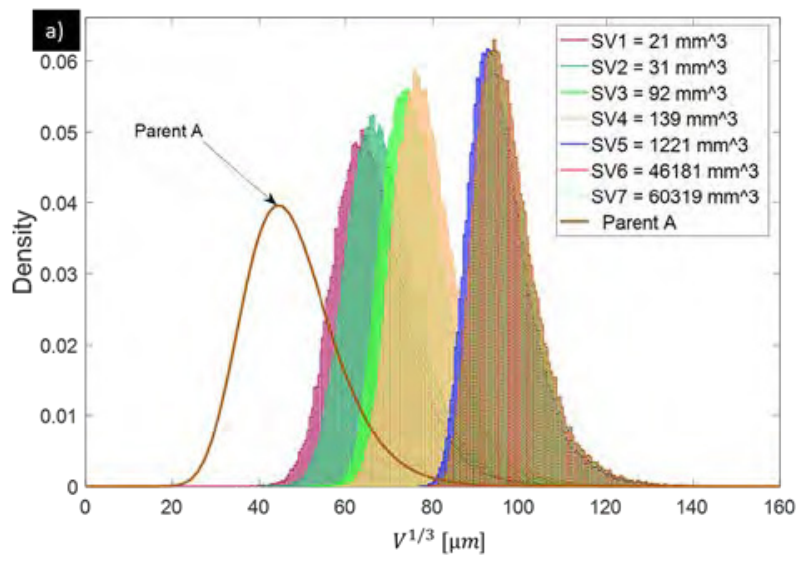




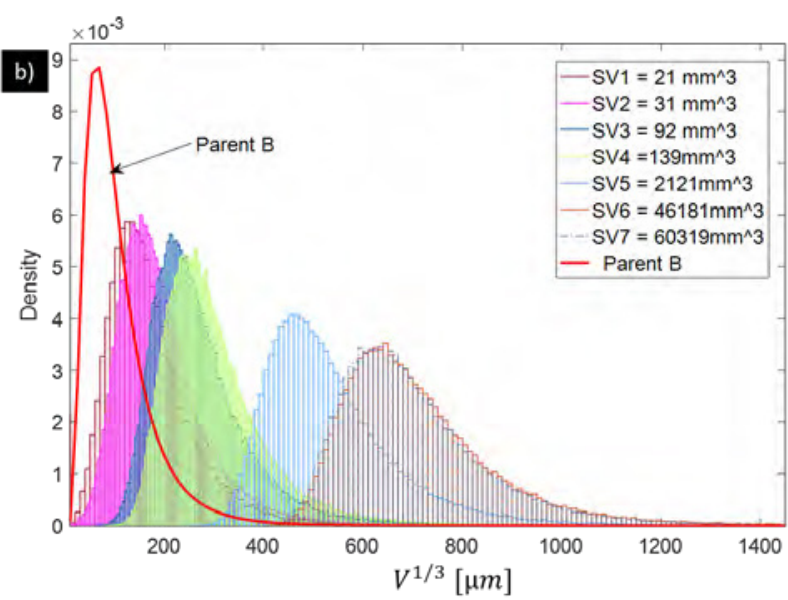

Fig. 13: Extreme value distributions for (a) A alloy and (b) B alloy as a function of sampling volume

In the following section the influence of the sampling volume on the Arithmetic Mean and Coefficient of Variation of critical defects size is discussed.

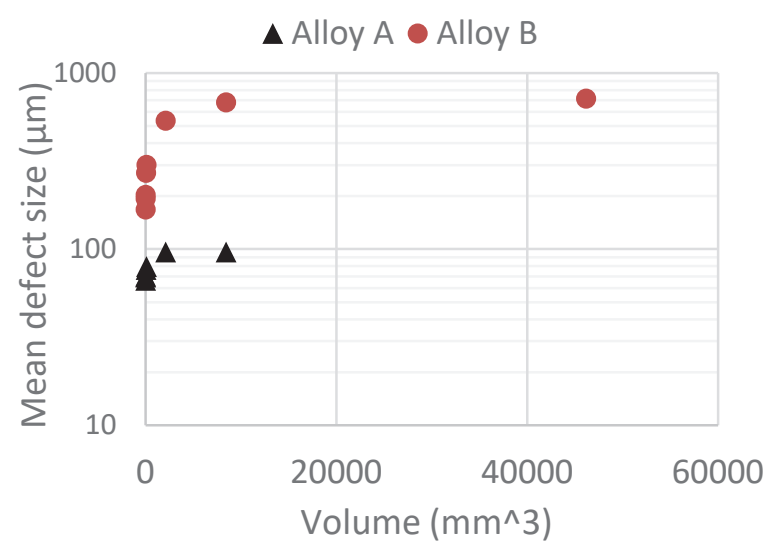

Fig. 14. Influence of the sampling volume on the arithmetic mean value of the critical defect size distributions.

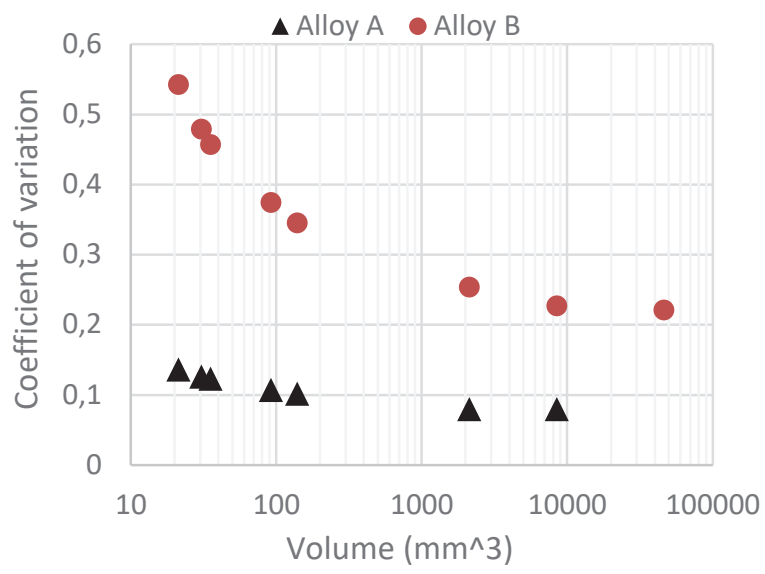

Fig. 15. Influence of the sampling volume on the coefficient of variation of critical defect size distributions.
Fig. 14 shows the evolution of the arithmetic mean value of the critical defect size distribution as a function of the sampling volume for both alloys.

In order to analyse the influence of the sampling volume on the scatter, Fig. 15 shows the evolution of the coefficient of variation as a function of the sampling volume. The coefficient of variation is defined as:

$$
C_{v}=\frac{\text { standard deviation, } s}{\text { mean value, } \mu}
$$

Both Fig. 14 and 15 highlight the fact that the distributions tend to a stabilized state as the sampling volume increases.

- For alloy A, it starts to stabilize from a volume of $2120 \mathrm{~mm}^{3}$. This can therefore be considered as the minimum value, above which the volume has no effect on the critical defect size for alloy A.

- For alloy B, it starts to stabilize from a volume of $8482 \mathrm{~mm}^{3}$. Hence, the minimum value for alloy B, above which the volume has no effect on the critical defect size, is much greater compared to alloy A.

It should be noted that these volumes are relatively large compared to the critical volumes determined for the fatigue specimens tested experimentally (see Table 3 ). Hence, a volume effect should be observed experimentally in terms of the critical defect size.

Also, it is important not to confuse these volumes (which are related to the defect size only) with the Fatigue ERV discussed in section 3.1. There is undoubtedly a direct relationship between the influence of the volume on the critical defect size and the influence of the volume on the fatigue strength (via the Kitagawa- Takahashi diagram), however this work is in-progress and will be discussed in future publications.

\section{Conclusions}

In this study, an experimental investigation has been conducted to evaluate the statistical size effect on the fatigue strength of cast Al-Si alloys. The main results can be summarized as follows:

- A variation in the highly stressed volume is accompanied by a change in the fatigue strength of the material. This result confirms the existence of a size effect in cast Al-Si alloys. Furthermore, alloy A has a more pronounced volume effect than alloy B. This must be due to the characteristics of the defect population of each alloy (pore size, distance between large pores, etc...).

- Good correlation between the local fatigue strength amplitude $\left(\mathrm{Kt}^{*} \sigma \mathrm{a}\right)$ and the critical volume was found. Hence, it can be concluded that the highly stress volume approach is an effective way to describe the statistical size effect in cast Al-Si alloys. 
- The fatigue strength for alloy A stabilizes from a critical volume of $320 \mathrm{~mm}^{3}$, which can be considered as the Fatigue Representative Elementary Volume.

- The fatigue strength of alloy B stabilizes at a smaller critical volume of $90 \mathrm{~mm}^{3}$ which can be considered as the Fatigue REV of this alloy.

- Both alloys are degraded by the same fatigue damage mechanism. In fact, on the Kitagawa-Takahashi diagram, both materials show the same tendency.

- The preliminary results of the numerical modelling approach highlight the influence of the volume on the critical defect size. It is demonstrated that the mean value of the critical defect size decreases with decreasing volume, but stabilises when the volume is greater than $2100 \mathrm{~mm}^{3}$ for Alloy A and greater than $8500 \mathrm{~mm}^{3}$ for Alloy B.

- The inverse trend is predicted for the dispersion. That is, the coefficient of variation of the critical defect distributions increases with decreasing volume.

PSA Groupe and the French National Agency for Research and Technology (ANRT) financially supported this work.

\section{References}

1. V. D. Le, Etude de l'influence des hétérogénéités microstructurales sur la tenue en fatigue à grand nombre de cycles des alliages d'aluminium de fonderie. (Doctoral dissertation, Angers, ENSAM). 2016.

2. I. Koutiri, Effet des fortes contraintes hydrostatiques sur la tenue en fatigue des matériaux métalliques. (Doctoral dissertation, Angers, ENSAM), 2011

3. C. E. Phillips, R. B. Heywood, "The size effect in fatigue of plain and notched steel specimens loaded under reversed direct stress.," p. 113-124., 1951.

4. J. E. Shigley, C. R. Mischke, Jr. T. H. Brown, "Standard Handbook of machine design. Third Edition". McGraw-Hill, New York 2004.

5. H. F. Moore, D. Morkovin, "Third progress report on the effect of size of specimen on fatigue strength of three types of steel." 1944.

6. N. Saintier, T. Palin-luc, J. Bénabes, F., "Cocheteux, Non-local energy based fatigue life calculation method under multiaxial variable amplitude loadings, International Journal of Fatigue," Sep2013.

7. A. Carpinteri, A. Spagnoli, Size effect in S-N curves: A fractal approach to finite-life fatigue strength. International Journal of Fatigue, 31, 927933. 2009

8. K. H. Kloos, A. Buch, D. Zankov, Pure geometrical size effect in fatigue tests with constant stress amplitude and in program tests. Materialwissenschaft und Werkstofftechnik. 12, 4050. 1981
9. M. Makkonen. Size effect and notch size effect in metal fatigue. Thesis for the degree of Doctor of Science (Technology), Lappeenranta University of Technology, Acta Universitatis Lappeenrantaensis 83; 1999

10. W. Weibull, 1939, the phenomenon of rupture in solids, In: Proc., Royal Swedish Institute of Engineering Research (Ingenioersvetenskaps Akad. Handl.), vol. 153, pp. 1-55 (Stockholm)

11. R. Kuguel, A relation between theoretical stress concentration factor and fatigue notch factor deducted from the concept of highly stressed volume, ASTM STP Proc; 61:732-48. 1961

12. C. M. Sonsino, G. Fischer, Local assessment concepts for the structural durability of complex loaded components. Materialwissenschaftund Werkstofftechnik. 36, 632-641. 2005.

13. C. K. Lin, W. J. Lee, Effects of highly stressed Volume on fatigue strength of austempered ductile irons. International Journal of Fatigue. 20. 301-307. 10.1016/S0142 1123(97)00134-5. 1998

14. DNV-RP-C203. Fatigue design of offshore steel structures; 2012.

15. API RP 2A-WSD. Recommended practice for planning, designing and constructing fixed offshore platforms - working stress design. 21st ed.; December 2000.

16. W. J. Dixon, A. M. Mood A Method for Obtaining and Analyzing Sensitivity Data, Journal of the American Statistical Association, p 43-241.1948

17. M. I. Houria, Y. Nadot, R. Fathallah, M. Roy D. M. Maijer, "Influence of casting defect and SDAS on the multiaxial fatigue behaviour of A356-T6 alloy including mean stress effect." 2015

18. P. Beiss, A. Zafari, K. Lipp, J. Baumgartner: Fatigue Behavior of a Sintered Steel Containing $4 \% \mathrm{Ni}, 1.5$ $\% \mathrm{Cu}, 0.5 \% \mathrm{Mo}$ and $0.6 \% \mathrm{C}$; Int. J. Powder Metal 48, p. 19-34. 2012

19. A. Zafari, P. Beiss, C. Broeckmann, K. Lipp: Assessing the Fatigue Strength of a Sintered Steel as affected by the Highly Stressed Volume; Proc. Euro PM, Barcelona, Vol.1, p.15-20; EPMA, Shrewsbury, 2011

20. A. Moesenbacher, C. Guster, G. Pinter, W. Eichlseder. Investigation of concepts describing the influence of stress concentration on the fatigue behaviour of short glass fibre reinforced polyamide. ECCM 2012 - Composites at Venice, Proceedings of the 15th European Conference on Composite Materials. 2012 